\title{
Athalamia as a late complication after keratoplasty on aphakic eyes
}

\author{
H. D. GNAD \\ From the First Eye Clinic, University of Vienna
}

SUMMARY In 3 cases of keratoplasty in aphakic eyes 4-8 months after surgery a gradual flattening of the anterior chamber was observed. During the initial postoperative months there was no suggestion of any impending complication. No synechiae at the anterior chamber angle were present, the anterior vitreous face had remained intact without being in contact with the posterior corneal surface, and the intraocular pressure remained within normal limits. Separation of anterior synechiae as well as vitrectomy via pars plana resulted merely in a temporary amelioration of this condition. Within a few days the anterior chamber was abolished again. The corneal buttons displayed epithelial oedema; the deeper layers, however, remained clear. Development of secondary glaucoma was kept under control either by appropriate medication or by cyclocryotherapy. The phenomenon reported here developed only in cases in which the anterior vitreous face had remained intact. It seems possible that this type of late complication may be avoided by prophylactic vitrectomy.

Whereas until a few years ago there was uncertainty whether a 2-stage operation or a combined operation was preferable in cases of corneal opacity and cataract, today the 1-stage combination of keratoplasty and cataract removal has largely prevailed. Fine $^{1}$ has alluded to the high probability of clouding of the transplant if the vitreous touches the posterior surface of the cornea. A number of authors have tried to develop a method to keep the anterior chamber free of vitreous. ${ }^{1-6}$ The main object is to ensure an intact anterior hyaloid membrane. As in the case of conventional cataract surgery, this is actually possible with appropriate hypotony even with a wide opening of the eyeball after trephination of the cloudy host cornea. But if the hyaloid membrane ruptures, and vitreous enters the anterior chamber, an anterior vitrectomy is advisible.

So far the results of perforating keratoplasty and simultaneous cataract extraction can be compared with those of keratoplasty on phakic eyes. Sautter ${ }^{7}$ records irreversible clouding of transplant in only $8 \%$ of cases. Arentsen, ${ }^{8}$ Capella, ${ }^{9}$ Kaufman, ${ }^{10}$ and Meyer ${ }^{11}$ have obtained clear transplants in $70-80 \%$ of their cases. The most frequent postoperative complication in the combined procedure as well as in keratoplasty in aphakic eyes is ocular hypertension. ${ }^{1012}$ Olson $^{12}$ points out that this is not unusual

Correspondence to Dr H. D. Gnad, I Univ.-Augenklinik, Spitalgasse 2, 1090 Vienna, Austria. even in patients who had normal tension preoperatively. He comes to the conclusion that virtually only those patients in whom preoperative glaucoma could be ruled out, or those whose tension did not exceed $27 \mathrm{mmHg}$ in the first postoperative week, have no protracted tension problems. Kaufman ${ }^{10}$ attributes postsurgical rise of tension to a pupillary block caused by vitreous hernia.

Most authors therefore suggest one or more peripheral iridotomies or iridectomies, as is usual in conventional cataract operations. Zimmerman and Olson $^{13}$ found a significant decrease in frequency of postoperative rise of tension in those cases in which the diameter of the donor cornea has exceeded that of the host flap by $0.5 \mathrm{~mm}$ on an average.

\section{Patients and methods}

During postoperative follow-up of patients on whom we had undertaken combined cataract-keratoplasty surgery or a corneal transplant for aphakia during the past 2 years we noticed a phenomenon which is not comparable to any reported observation on this subject. In 3 patients we detected about 4-8 months postoperatively an advancing flattening of the anterior chamber. During the first few months after surgery the postoperative course was essentially inconspicuous. There were no goniosynechiae, the intact anterior hyaloid membrane had no contact with the cornea, and tension was within the normal 
range. We have therefore searched our files of patients operated on within the past 2 years in order to discover from the surgical notes and the notes on the postoperative course a pointer to the cause of this phenomenon. Of the 72 perforating keratoplasties performed during this period 7 were done on aphakic eyes. In 9 cases corneal grafting was combined with cataract extraction. Anterior vitrectomy was necessary in 4 aphakic eyes, and twice during combined procedure.

CASE 1

Female, born 4 February 1896. Bilateral cornea guttata, iridoschisis in the inferior nasal quadrant, and nuclear cataract. 24 October 1974: Cryoextraction of lens in the right eye with total iridectomy. No complications in the vitreous. Postoperative development of a therapy-resistant bullous keratopathy with adhesions of the anterior iris layer with thickened cornea in the region of iridoschisis. These adhesions were separated on 22 April 1975 and the anterior chamber was filled with Ringer's solution. 12 January 1977: perforating keratoplasty right eye $(7 \cdot 0 / 7 \cdot 1 \mathrm{~mm}$ diameter). Anterior hyaloid membrane remained intact. The case healed initially without complications, the graft remained clear, the anterior chamber was deep, and even in the area of iridoschisis there was no corneal contact. On 13 May 1977 the anterior chamber had disappeared peripherally, and a flat chamber was present only at the centre. The corneal graft showed epithelial oedema, tension $27 \mathrm{mmHg}$. Over the next few weeks the anterior chamber flattened completely. Owing to the poor general health of the patient no further surgical intervention was undertaken. The intraocular tension could be controlled satisfactorily with $2 \%$ Piladren (pilocarpine $20 \mathrm{mg}$ and adrenaline $20 \mathrm{mg}$ per $\mathrm{ml}$ ) drops thrice daily, and thereafter the graft remained clear. On 23 August 1978 the patient had vision 6/12, Jaeger 3-4, with contact lens.

CASE 2

Female, born 15 September 1905. Bilateral corneal scars following eczematous keratitis mainly in the right eye and anterior and posterior cortical cataract. 26 April 1974: cryoextraction of cataract left eye. 24 January 1977: perforating keratoplasty $(7 \cdot 0 / 7 \cdot 1$ $\mathrm{mm}$ diameter) and cryoextraction of cataract right eye; the anterior hyaloid membrane remained intact. 17 August 1977: removal of running Tübinger-suture. At postoperative examination on 12 September 1977, the anterior chamber was flattened peripherally, one week later completely. The graft remained clear. 20 September 1977: separation of synechiae and air injection into anterior chamber. After absorption of the air bubble, the anterior chamber flattened again; dilatation of the pupil by mydriatics showed posterior synechiae to the vitreous. 11 October 1977: vitrectomy through pars plana with the Klöti-vitreophage and air injection into the anterior chamber, the latter, however, flattening shortly thereafter. Because of raised intraocular pressure cryopexy was performed twice during the following months; the tension, however, could not be controlled satisfactorily. Finally the graft was cloudy, somewhat oedematous, and the anterior chamber was abolished. Vision was reduced to doubtful light projection and perception of hand movements close to the eye.

\section{CASE 3}

Female, born 28 December 1901. Mature cataract left eye, nuclear cataract right eye, bilateral cornea guttata. 16 November 1976: cryoextraction of cataract left eye, postoperative development of a therapy resistant bullous keratopathy; on 18 February 1977 a perforating keratoplasty (7.0/7.5 $\mathrm{mm}$ diameter) was performed. The anterior hyaloid membrane remained intact. Postoperatively the graft was clear and the anterior chamber deep; the intraocular tension remained normal. On 25 May 1977 the anterior chamber had flattened, anterior synechiae were not present. On 20 June 1977 the anterior chamber existed only in the pupillary area, the iris lay close to the posterior corneal surface circularly, the vitreous had no corneal contact. 21 June 1977: posterior sclerotomy was performed, anterior synechiae were separated and the anterior chamber was filled with Ringer's solution. A few days later the anterior chamber was flattened again. The tension could be regulated to some extent by cyclocryopexy. 25 August 1977: vitrectomy via pars plana with the Klöti-vitreophage, separation of anterior synechiae, and filling of anterior chamber with Ringer's solution. Thereafter the anterior chamber stayed only for a few days. A cyclodialysis and a renewed cyclocryopexy effected no enduring success. Finally, vision was reduced to perception of hand movements close to the eye and deficient light projection. The graft showed epithelial oedema; stroma was clear.

\section{Discussion}

Anterior synechiae, particularly goniosynechiae accompanied by secondary glaucoma in aphakic eyes after corneal grafting, are not unusual. A likely cause would be retrocorneal membranes forming after destruction of endothelial cells of the corne $\mathrm{a}^{14}$ or occasionally epithelial invasion. ${ }^{15} \mathrm{Böke}^{16}$ observed anterior synechiae mostly in cases of 


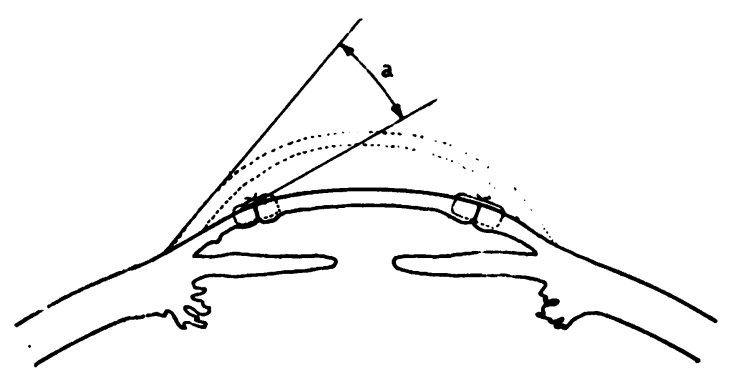

Fig. 1 Change in corneolimbal angle (a) after penetrating keratoplasty when using same size donor button as recipient bed ${ }^{18}$

recurring inflammation, as in herpetic keratitis or if the keratoplasty was accompanied by loss of vitreous. In our cases we saw similar anterior synechiae after anterior vitrectomy; however, these adhesions were separable and did not show a tendency to indirect athalamia.

Zimmerman and Olson ${ }^{1317}$ developed a mathematical model which depicts the relationship between the technique of a keratoplasty and the width of the chamber angle (Fig. 1). Accordingly, large grafts, small donor corneas, and extensively and closely placed sutures ${ }^{18}$ lead, through gathering up of the tissues, to a narrowing of the chamber angle, provoking the liability to secondary glaucoma. The authors suggest that the structures of the iridocorneal chamber angle are held stable by an anterior and posterior support mechanism. Anteriorly Descemet's membrane and the line of Schwalbe and posteriorly the lens, the zonule fibres, and the ciliary body seem to be a prerequisite for the maintenance of the chamber angle.

As by combined cataract keratoplasty surgery both supporting mechanisms are involved, one can imagine that aphakia may promote the development of a secondary glaucoma after keratoplasty. With this concept of diminution of the anterior segment of the eye in mind one can also explain the slow increase of flattening of the anterior chamber which could be observed in our cases. The solid vitreous body firmly fixed to the vitreous base can shift only within limits into the subvitreal fluid area in cases of posterior vitreous detachment. The iris diaphragm rests on the anterior hyaloid membrane with far more tension than in a case of simple aphakia. The aqueous flow to the anterior chamber is impeded despite iridectomy, which usually cannot be made quite peripherally in the course of combined keratoplasty cataract operation. Finally adhesions between iris and vitreous could further increase the resistance of outflow. The phenomenon of postoperative flattening and abolition of the anterior chamber of aphakic eyes after keratoplasty was exclusively encountered in cases in which the anterior hyaloid membrane remained intact during the operation. It is conceivable that this late complication might not have occurred after a preventive anterior vitrectomy. Further studies of that possibility are indicated.

\section{References}

${ }^{1}$ Fine M. Penetrating keratoplasty in aphakia. Arch Ophthalmol 1964; 72: 50-6.

${ }^{2}$ Barraquer J. Present status of corneal transplant surgery. Highlights Ophthalmol 1962; 5: 320-7.

${ }^{3}$ Filatov VP. Transplantation of cornea. Arch Ophthalmol 1935; 13: 321-47.

${ }^{4}$ Lempert SL, Jenkins MS, Brown SB. Prevention of vitreous loss in aphakic keratoplasty. Am $J$ Ophthalmol 1978; 86: 59-60.

${ }^{5}$ Sommer G. Safeguards during keratoplasty in aphakic eyes. Klin Monatsbl Augenheilkd 1959; 134: 72-8.

'Thomas CI. Corneal transplantation in cases of aphakia and ectopia of the lens. Arch Ophthalmol 1949; 42: 389-411. ${ }^{7}$ Sautter H, Naumann G, Demeler B. Über Erfahrungen mit gleichzeitiger perforierender Keratoplastik und Kataraktextraktion. Klin Monatsbl Augenheilkd 1973; 163: 290-8.

${ }^{8}$ Arentsen JJ, Laibson PR. Penetrating keratoplasty and cataract extraction. Arch Ophthalmol 1978; 96: 75-6.

'Capella JA, Kaufman HE, Polack FM. Prognosis of keratoplasty in phakic and aphakic patients and use of cryopreserved donor tissue. Trans Am Acad Ophthalmol Otolaryngol 1972; 76: 1275-85.

${ }^{10} \mathrm{Kaufman}$ HE. Combined keratoplasty and cataract extraction. Am J Ophthalmol 1974; 77: 824-9.

${ }^{11}$ Meyer HJ. Perforierende Keratoplastik bei Aphakie. Klin Monatsbl Augenheilkd 1974; 164: 453-62.

${ }^{12}$ Olson RJ, Kaufman HE. Prognostic factors of intraocular pressure after aphakic keratoplasty. Am J Ophthalmol 1978; 86: 510-15.

${ }^{13}$ Zimmerman TJ, Olson R, Waltman S, Kaufman HE. Transplant size and elevated intraocular pressure. Arch Ophthalmol 1978; 96: 2231-3.

${ }^{14}$ Michels RG, Kenyon KR, Maumenee AE. Retrocorneal fibrous membrane. Invest Ophthalmol 1972; 11: 822-31.

${ }^{15}$ Sugar A, Meyer RF, Hood J. Epithelial downgrowth following penetrating keratoplasty in the aphake. Arch Ophthalmol 1977; 95: 464-8.

${ }^{16}$ Böke W. Perforierende Keratoplastik. Klin Monatsbl Augenheilkd 1977; 171 : 656-77.

${ }^{17}$ Olson RJ. Aphakic keratoplasty. Arch Ophthalmol 1978; 96: 2274-6.

${ }^{18}$ Zimmerman TJ, Krupin T, Grodzki W. The effect of suture depth on outflow facility in penetrating keratoplasty. Arch Ophthalmol 1978; 96: 505-6. 